\title{
Perinatal Endotoxemia Induces Sustained Hepatic COX-2 Expression through an NFKB-Dependent Mechanism
}

\author{
Sarah McKenna ${ }^{a}$ Molly Eckman ${ }^{a}$ Andrew Parker ${ }^{a}$ Rachael Bok ${ }^{b}$ \\ K. Joseph Hurt ${ }^{\mathrm{b}}$ Clyde J. Wright ${ }^{\mathrm{a}}$ \\ a Section of Neonatology, Department of Pediatrics, and b Divisions of Reproductive Sciences and Maternal Fetal \\ Medicine, Department of Obstetrics and Gynecology, University of Colorado School of Medicine, Aurora, Colo., USA
}

\section{Key Words}

Endotoxin $\cdot$ Immune response $\cdot$ Macrophages .

NF-kappa B C COX-2

\begin{abstract}
Background: Exposure to perinatal infection is associated with the multiple morbidities complicating preterm birth. How a relatively immature innate immune response contributes to this is unknown. Objective: We sought to determine if the perinatal innate immune response to endotoxemia induces a unique pattern of cyclooxygenase-2 (COX-2) expression via an NFKB-dependent mechanism. Methods: Hepatic and pulmonary COX-2 mRNA expression was assessed following perinatal (at embryonic days 15 and 19 and after birth) or adult endotoxemia. Hepatic NFKB activity was assessed by cytosolic inhibitory protein degradation and subunit nuclear translocation. Immunohistochemistry and isolated cell preparations determined hepatic macrophage COX-2 expression, and the effect of pharmacologic and genetic inhibition of NFKB activity was tested. Results: Perinatal endotoxemia induced sustained hepatic macrophage COX-2 expression and NFKB activity compared to in exposed adults. Isolated hepatic macrophages and immunohisto-
\end{abstract}

\section{KARGER}

E-Mail karger@karger.com

www.karger.com/jin chemistry demonstrated enriched LPS-induced COX-2 expression that was sensitive to pharmacologic and genetic approaches to attenuate NFKB activity. Finally, pharmacologic inhibition of endotoxemia-induced NFKB activity in neonatal mice prevented hepatic NFKB activity and attenuated COX-2 expression. Conclusion: Our findings of sustained neonatal hepatic NFKB activity and COX-2 expression in response to endotoxemia support a robust perinatal innate immune response. This may represent a link between the innate immune response and the pathogenesis of diseases associated with preterm birth.

(c) 2016 S. Karger AG, Basel

\section{Introduction}

Preterm birth affects $5-18 \%$ of all pregnancies and represents an enormous health care burden [1]. Preterm birth brings with it early and repetitive stimulation of the innate immune response. Infection is associated with 40$60 \%$ of all preterm births [2], and $20-40 \%$ of infants born at $<28$ weeks gestation experience sepsis prior to discharge [3]. These repeated infectious exposures are independent risk factors for mortality and the long-term mor- 
bidities associated with prematurity $[4,5]$. Whether the neonatal innate immune response to these infectious stimuli contributes to the pathogenesis of these complications is unclear.

Inducible COX-2 expression is a key component of the Toll-like receptor 4 (TLR4)-mediated innate immune response [6]. In adults, numerous studies have demonstrated that increased COX-2 expression contributes to the pathogenesis of septic shock in adults [7]. While COX-1 expression is constitutive, COX-2 expression is inducible and regulated at the transcriptional level in an organ- and cell type-specific manner $[8,9]$. The adult liver, in contrast to the lung, is an important source of inducible COX-2 expression following stimulation of the innate immune response [8].

While it is generally accepted that the neonatal innate immune response is immature, defective, and biased against a proinflammatory response [10], clinical data support the presence of increased COX-2 activity in premature infants exposed to inflammatory stress. Exposure to either chorioamnionitis or early-onset sepsis increases the risk of developing a patent ductus arteriosus (PDA) [11, 12]. Importantly, PDA associated with infection is associated with increased circulating prostaglandin and prostaglandin metabolites, including 6-keto-PGDF1 [11]. Additionally, it has recently been demonstrated that increased prostaglandin E2 (PGE2) complicates sepsis and meningitis in preterm infants [13]. It is unclear whether exposure to perinatal inflammation induces COX-2 expression, which would explain these observed increases in circulating prostaglandin. Furthermore, whether this occurs in an organ- and cell type-specific manner similar to in adults is unknown. If robust COX-2 expression is central to the neonatal innate immune response, these clinical observations would appear to contradict the current paradigm that the neonatal innate immune response is impaired.

It has long been recognized that in adult animals, endotoxemia induces both pulmonary and hepatic NFKB activation [14]. It is important to recognize that these observations do not predict the neonatal response to endotoxemia. In fact, previous studies have shown that pulmonary NF $\kappa B$ activation induced by endotoxemia in neonatal mice is fundamentally different from that observed in adults [15]. This is a critical observation, and it is consistent with a growing body of literature demonstrating that $\mathrm{NF \kappa B}$-regulated target gene expression is developmentally regulated [15-17]. Importantly, whether differences exist between neonatal and adult hepatic NFKB activity during endotoxemia is unknown. In quiescent cells,

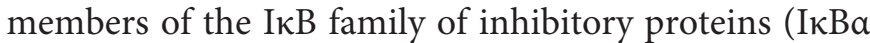

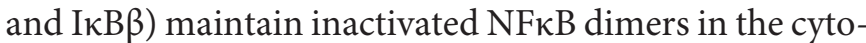
plasm [18]. Following exposure to inflammatory stimuli (e.g. lipopolysaccharide, LPS), IкBs are phosphorylated and degraded, allowing NFKB nuclear translocation [18]. The kinetics of I $\mathrm{B}$ degradation dictate NFkB activity and can thus be used as a marker of NFKB transcriptional activity [19]. Furthermore, although NFKB is a key determinant of the transcriptome following stimulation of the innate immune response, whether it regulates hepatic COX-2 expression in response to endotoxemia remains unknown. Thus, we undertook this study to better understand the role of developmentally regulated NFkB activity and the effect on tissue-specific COX-2 expression.

\section{Methods}

\section{Murine Model of Endotoxemia}

Fetal Endotoxemia. C57/BL/6 timed pregnant mice were purchased from Charles River Laboratories for these experiments. Fetal endotoxemia was induced as previously described [20] using a validated model of intrauterine inflammation which results in $100 \%$ preterm birth and no maternal mortality. The mice were mated and the day the plug was found was considered embryonic day 0.5 (e0.5). As the C57/BL/6 strain routinely has a 20-day gestation, survival surgery and intrauterine injections of LPS (or vehicle control) were performed on e15.5 (preterm studies) and e19.5 (term studies). Briefly, a continuously inhaled isofluorane/oxygen anesthesia (5\%) was administered and after deep anesthesia was reached (as determined by toe pinch), the inhalation mixture was maintained at $1.5-3 \%$ for the duration of the procedure. A small laparotomy was performed in the lower abdomen, the right and left uterine horns were isolated, and either LPS $(250 \mu \mathrm{g}$ in $200 \mu \mathrm{l}$ normal saline; from Escherichia coli, 055:B5, Sigma-Aldrich) or an equal volume of normal saline (control) was infused equally ( $100 \mu \mathrm{l} /$ horn) into each horn of the uterus between the first and second gestational sac closest to the cervix. The exposed uterus was washed with $500 \mu \mathrm{l}$ normal saline, and a mixture of $0.5 \%$ lidocaine (in $200 \mu \mathrm{l}$ normal saline) was injected into the peritoneal cavity before routine closure of the incision was performed. The dams were allowed to recover in individual cages and were euthanized for tissue collection after successfully delivering their first pup, with the matched saline-control animals being sacrificed at the same time. In this study, all dams injected at e 15 went into preterm labor within $16 \mathrm{~h}$ of intrauterine LPS injection, while all dams injected at e19 went into preterm labor within $6 \mathrm{~h}$ of the injection. For gene expression studies, tissues were collected from the 4 pups adjacent to the injection site of each uterine horn.

Postnatal Endotoxemia. Neonatal or adult ICR (wild-type, WT) mice were exposed to lethal $(50 \mathrm{mg} / \mathrm{kg}$, defined as $>90 \%$ mortality by $48 \mathrm{~h}$ ) or sublethal $(5 \mathrm{mg} / \mathrm{kg}$, defined as $>90 \%$ survival at $72 \mathrm{~h}$ ) doses of LPS (phenol purification; catalog No. L2630, Sigma) by intraperitoneal (i.p.) injection or received BAY 11-7085 pretreatment (1-20 mg/kg) $1 \mathrm{~h}$ prior to LPS exposure by i.p. injection followed by LPS exposure (i.p., $50 \mathrm{mg} / \mathrm{kg}, 2 \mathrm{~h}$ ). LPS doses were determined by mortality curves (data not shown) with $50 \mathrm{mg} / \mathrm{kg}$ LPS demonstrating $90 \%$ mortality and $5 \mathrm{mg} / \mathrm{kg}$ LPS demonstrating 
$<10 \%$ mortality at $24 \mathrm{~h}$ in neonatal mice. Following exposure, mice were sacrificed and normal saline was perfused through the right ventricle, and liver and lung samples were collected and processed as described below. All procedures were approved by the Institutional Animal Care and Use Committee at the University of Colorado (Aurora, Colo., USA).

\section{Primary Cell Collection}

Hepatocytes and macrophages were collected from neonatal livers by gradient centrifugation as previously described [21]. Following collection, cells were lysed in buffer RLT and RNA was collected using the RNeasy Mini Kit (Qiagen) according to the manufacturer's instructions.

\section{Tissue Processing}

Whole-Cell Lysate. Liver tissue was homogenized in T-PER (Thermo Scientific) lysis buffer with protease/phosphatase inhibitors (HALT, Thermo) using the Bullet Blender $(0.5-\mathrm{mm}$ glass beads or 1.0-mm zirconium oxide beads; speed 7, 5 min). Protein content of the supernatant was determined by Bradford assay.

Cytosolic and Nuclear Extraction. Cytosolic and nuclear extracts were collected from liver tissue using the NE-PER kit (Pierce) according to the manufacturer's instructions, with some modifications. Specifically, following collection of the cytosolic extract, the nuclear pellet was washed and resuspended in cytosolic extraction reagent to completely remove the remaining cytosolic fraction.

mRNA Isolation and cDNA Synthesis. Total RNA was isolated using the RNeasy Mini Kit (Qiagen) on $30 \mathrm{mg}$ of lung tissue homogenized in RLT buffer in a Bullet Blender $(0.5-\mathrm{mm}$ glass beads or 1.0-mm zirconium oxide beads; speed 7, 5 min; NextAdvance). Following homogenization, supernatants were removed and RNA was immediately collected using the RNeasy Mini Kit (Qiagen) according to the manufacturer's instructions. RNA was assessed for purity and concentration using the NanoDrop (ThermoFisher Scientific), and cDNA synthesized using the Verso cDNA synthesis kit (Thermo Scientific).

Immunohistochemistry. Frozen, OCT-embedded neonatal livers were cut into $7-\mu \mathrm{m}$ sections. Sections were fixed with $4 \% \mathrm{PFA}$, blocked and then incubated with COX-2 (Santa Cruz) and F4/80 pan macrophage marker (Abcam) primary antibodies and visualized with the Olympus IX83 microscope and Olympus DP80 camera at $\times 40$ magnification. Sequential images were processed and superimposed using Olympus CellSens software. To assess macrophage numbers, sections were visualized on an inverted Olympus IX83 microscope $(\times 20)$ using an Olympus DP80 camera and Olympus CellSens software. Macrophage numbers were determined by counting the number of F4/80 staining cells per highpowered field. Five high-powered fields from the livers from 3 separate animals per exposure were assessed.

PGE2 ELISA. To assess hepatic COX-2 activity, lysates were prepared from the neonatal liver and the protein content was determined as described above. PGE2 was purified from liver homogenate following protein removal by acetone precipitation and PGE2 ELISA was performed with a PGE2 ELISA kit (Enzo) according to the manufacturer's instructions.

\section{Cell Culture and LPS Exposure}

RAW 264.7 macrophages (ATCC) were cultured according to the manufacturer's instructions. Bone marrow-derived macrophages (BMDM) were collected from male ICR mice (6-10 weeks old) and cultured as previously described [21]. Cells were exposed to LPS ( $1 \mu \mathrm{g} / \mathrm{ml}$; catalog No. L5418, Sigma) and RNA was collected using the RNeasy Mini Kit (Qiagen).

$N F \kappa B$ Inhibition in vitro

RAW 264.7 cells were pretreated with the pharmacologic NFKB inhibitors BAY 11-7085 or parthenolide (both 1-20 $\mu \mathrm{M}$, Sigma) for $1 \mathrm{~h}$ prior to LPS exposure and maintained in the medium throughout the exposure. Alternatively, RAW 264.7 cells were transfected using Lipofectamine 2000 following the manufacturer's instructions with WT or dominant negative (DN) I $\mathrm{Ba}$ a vectors (Clontech) prior to LPS exposure.

\section{Immunoblot Analysis}

Lysates and cytosolic extracts were electrophoresed on a 4-12\% polyacrylamide gel (Invitrogen) and proteins were transferred to an Immobilon membrane (Millipore). Membranes were blotted with anti-IкBa (Santa Cruz Biotechnologies No. 371), anti-IкB $\beta$ (Santa Cruz Biotechnologies No. 9130), anti-COX-2 (Santa Cruz Biotechnologies No. 1745), anti-p65 (Cell Signaling \#8242), antilamin B (Santa Cruz Biotechnologies No. 6217) and anti-Calnexin (Enzo Life Sciences ADI-SPA-860). Densitometric analysis was performed using ImageLab (Bio-Rad).

Analysis of Relative mRNA Levels by RT-qPCR. Relative mRNA levels were evaluated by quantitative real-time PCR using the TaqMan gene expression system (Applied Biosystems). Gene expression of COX-2 was assessed with predesigned exon-spanning primers (Mm00478374_m1) using the StepOnePlus real-time PCR system (Applied Biosystems). Relative quantitation was performed via normalization to the endogenous control $18 \mathrm{~S}$ using the cycle threshold $(\Delta \Delta \mathrm{Ct})$ method.

\section{Statistical Analysis}

For comparison between treatment groups, the null hypothesis that no difference existed between treatment means was tested by Student's t test for 2 groups and 2-way ANOVA for multiple groups with potentially interacting variables (organ, duration of exposure), with the statistical significance between and within groups determined by means of Bonferroni's method of multiple comparisons (InStat, GraphPad software, Inc.). Statistical significance was defined as $\mathrm{p}<0.05$.

\section{Results}

\section{Endotoxemia Induces Hepatic COX-2 Expression in} Fetal, Neonatal and Adult Mice

For this study, we compared LPS-induced pulmonary and hepatic COX-2 expression in fetal, neonatal and adult mice. We observed no significant change in pulmonary COX-2 expression in response to systemic inflammatory stress in the e15 or the e19 fetal mice (fig. 1a, b), in neonatal and adult mice exposed to lethal endotoxemia (50 $\mathrm{mg} / \mathrm{kg}$ i.p.; fig. 1c, d), or in neonatal and adult mice exposed to sublethal endotoxemia ( $5 \mathrm{mg} / \mathrm{kg}$ i.p.; fig. 1e, f). In contrast, endotoxemia induced robust hepatic COX-2 
expression in e15 fetal and e 19 fetal mice, and in neonatal and adult mice exposed to either lethal or sublethal endotoxemia (fig. 1a-f). These results show that endotoxemia does not result in increased pulmonary COX-2 expression in fetal, neonatal and adult mice. Of note, endotoxemia significantly increased the pulmonary expression of
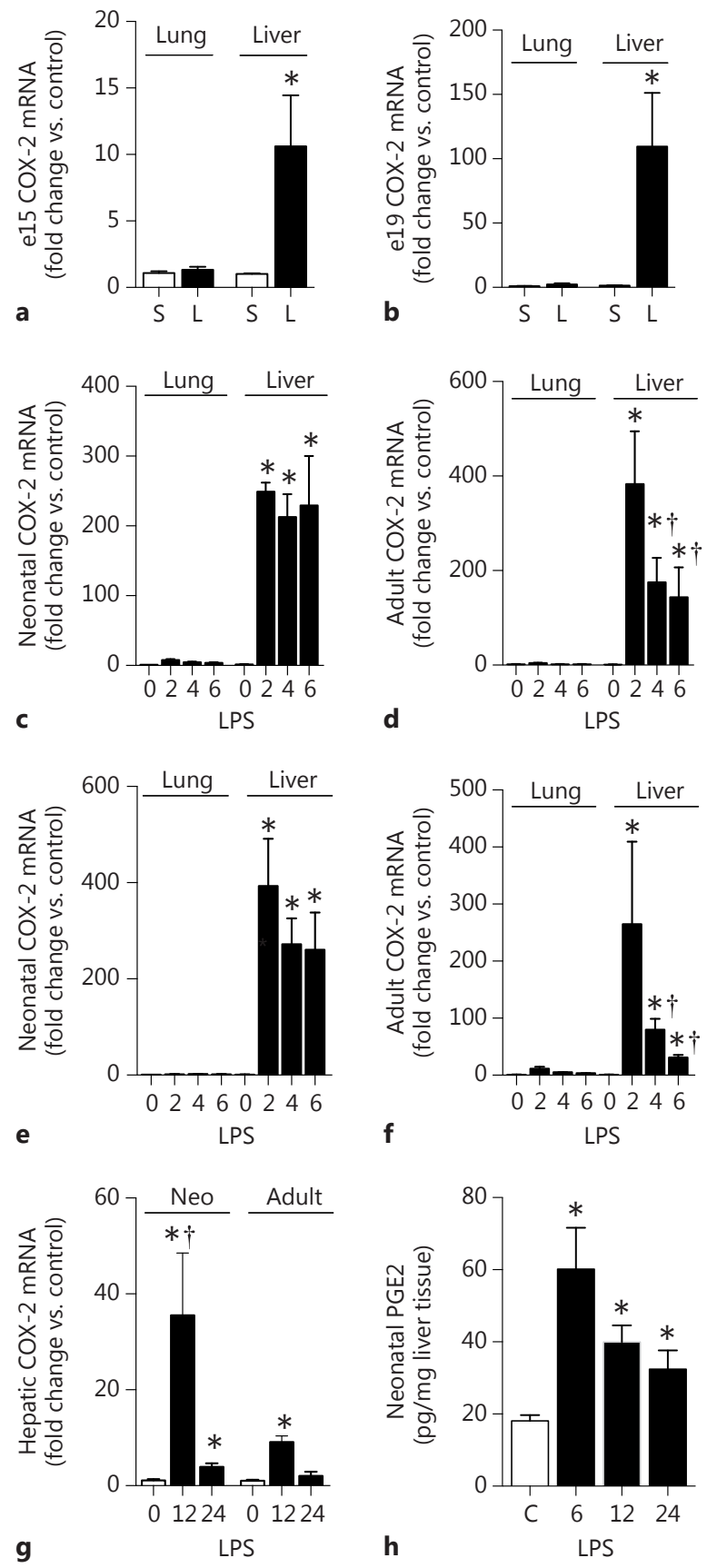

IL1 $\beta$ and IL6 in fetal, neonatal and adult mice (data not shown), indicating that the differences observed in COX2 expression could not be explained by an absence of inflammatory stimulus being delivered to the lung. However, endotoxemia induces robust hepatic COX-2 expression in fetal, neonatal and adult mice.

Of note, differences in the kinetics of LPS-induced hepatic COX-2 expression were observed between neonatal and adult mice. Following exposure to either lethal or sublethal endotoxemia, neonatal hepatic COX-2 expression remained persistently elevated through $6 \mathrm{~h}$ of exposure (fig. 1c, e). In contrast, at this time point, adult hepatic COX-2 expression was significantly lower than peak expression at $2 \mathrm{~h}$ of exposure (fig. $1 \mathrm{~d}, \mathrm{f}$ ). This observation prompted us to evaluate neonatal and adult hepatic COX2 expression at extended points following exposure to sublethal endotoxemia. At later time points (12 and $24 \mathrm{~h}$ ), neonatal hepatic COX-2 expression remained significantly elevated compared to adult levels (fig. 1g). Importantly, increased hepatic COX-2 expression was associated with significantly increased hepatic PGE2 expression in neonatal mice at 6,12 and $24 \mathrm{~h}$ after LPS exposure (fig. 1h). The unique kinetics of COX-2 mRNA expression in response to endotoxemia observed in the neonatal liver led us to investigate whether differences in the transcriptional regulation of COX-2 explained these differences.

\section{Endotoxemia Induces Hepatic NFאB Activation in \\ Neonatal Mice}

Transcription is the rate-limiting step in COX-2 expression [9], but the transcriptional mechanisms underlying increased hepatic COX-2 expression during endotoxemia in vivo are unknown. Thus, we sought to define the signaling mechanisms underlying endotoxemia-in-

Fig. 1. Endotoxemia induces hepatic but not pulmonary COX-2 expression in fetal, neonatal and adult mice. Fold increase in LPSinduced COX-2 expression in e15 (a) and e19 (b) fetal liver and lung following intrauterine saline (S) or LPS (L) exposure $(250 \mu \mathrm{g}$, approx. $4 \mathrm{~h}$ ), neonatal (c) and adult (d) lung and liver following exposure to lethal endotoxemia (50 mg/kg i.p., 0-6 h), neonatal (e) and adult (f) lung and liver following exposure to sublethal endotoxemia (LPS, $5 \mathrm{mg} / \mathrm{kg}$ i.p., $0-6 \mathrm{~h}$ ) and neonatal and adult liver (g) following exposure to sublethal endotoxemia (LPS, $5 \mathrm{mg} / \mathrm{kg}$ i.p., 12 and $24 \mathrm{~h}$ ). Data are expressed as means \pm SEM; $n=4 /$ time point. ${ }^{*} \mathrm{p}<0.05$ versus unexposed control; ${ }^{\dagger} \mathrm{p}<0.05$ versus $2 \mathrm{~h}$ exposure $(\mathbf{d}, \mathbf{f}, \mathbf{g})$ or time-matched adult. $\mathbf{h}$ PGE2 concentration in neonatal liver following LPS exposure ( $5 \mathrm{mg} / \mathrm{kg}, 6-24 \mathrm{~h}$ ). C = Control. Data expressed as means \pm SEM relative to unexposed control; $n=6-8$ / time point. ${ }^{*} \mathrm{p}<0.05$ versus unexposed control. 


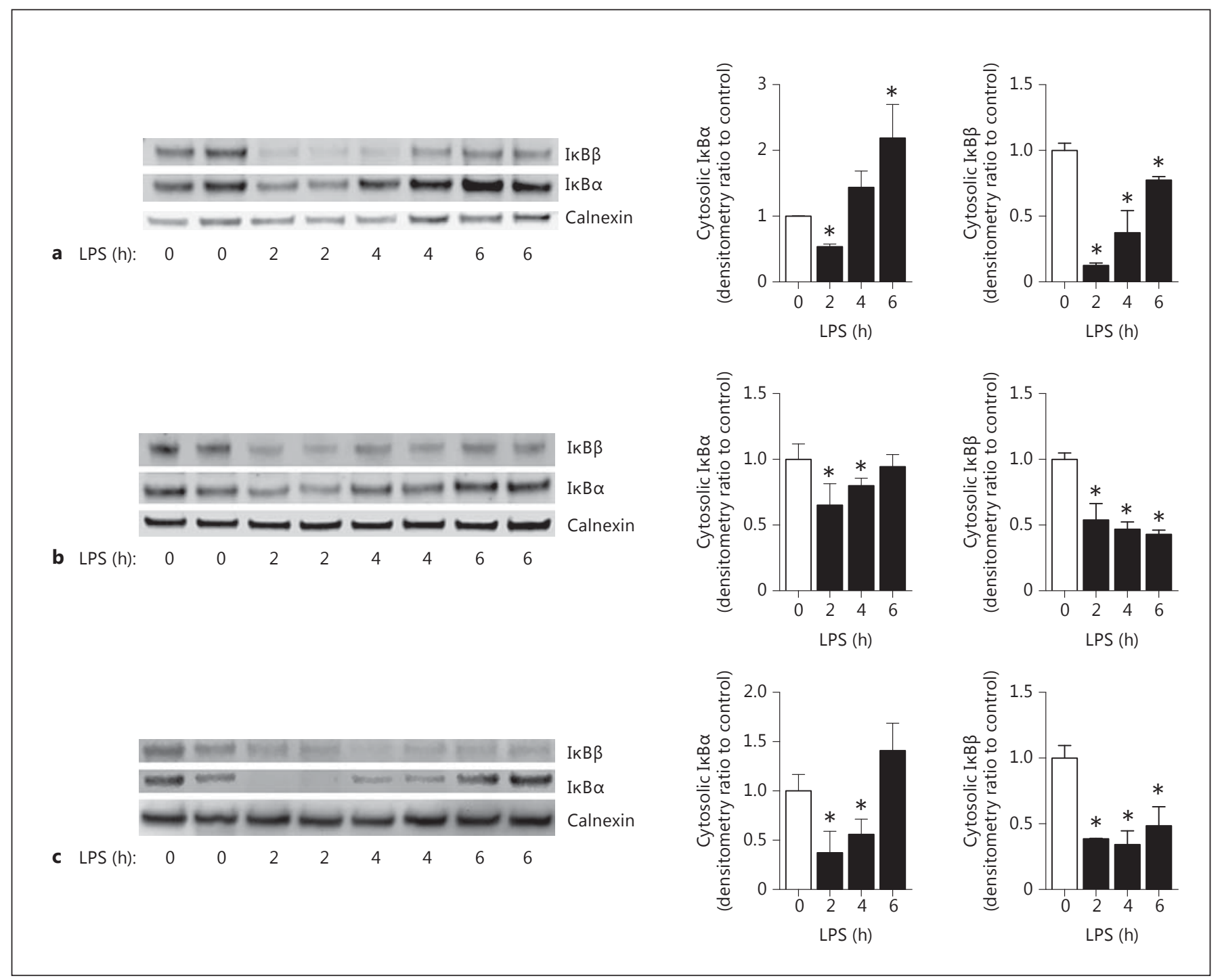

Fig. 2. LPS-induced hepatic COX-2 expression is temporally associated with $\mathrm{NF \kappa B}$ activation. a, b Representative Western blot

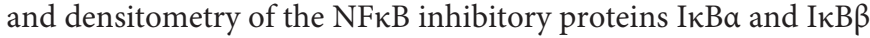
in hepatic cytosolic fractions following sublethal endotoxemia (5 mg/kg i.p., 0-6 h) with calnexin as loading control in adult (a) and neonatal (b) mice. c Representative Western blot and densi-

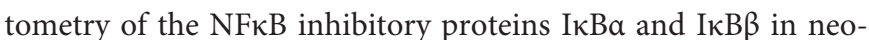
natal hepatic cytosolic fractions following lethal endotoxemia (50 mg/kg i.p., 0-6 h) with calnexin as loading control. Data are expressed as means \pm SEM; $\mathrm{n}=4-6 /$ time point. ${ }^{*} \mathrm{p}<0.05$ versus unexposed control. duced hepatic COX-2 expression. Previous studies have demonstrated that multiple transcription factors regulate COX-2 expression in response to various stimuli, including NFkB [9]. Because NFkB activation and target gene expression are developmentally regulated and we had observed developmental differences in the kinetics of hepatic COX-2 expression during endotoxemia, we speculated on whether there were differences in the kinetics of hepatic NFkB activation during endotoxemia between neonatal and adult mice. We have previously demonstrated that in adult mice, lethal endotoxemia acutely (within $2 \mathrm{~h}$ ) induces $\mathrm{NFKB}$ activation as measured by $\mathrm{I} \kappa \mathrm{B} \alpha$ and $\mathrm{I} \kappa \mathrm{B} \beta$ degradation [21]. However, the kinetics of $\mathrm{I} \kappa \mathrm{B}$ degradation following exposure to sublethal endotoxemia have not been reported in adult mice and the kinetics of I $\mathrm{B}$ B degradation following exposure to lethal or sublethal endotoxemia have not been reported in neonatal mice. Thus, to determine if LPS-induced hepatic NFKB 

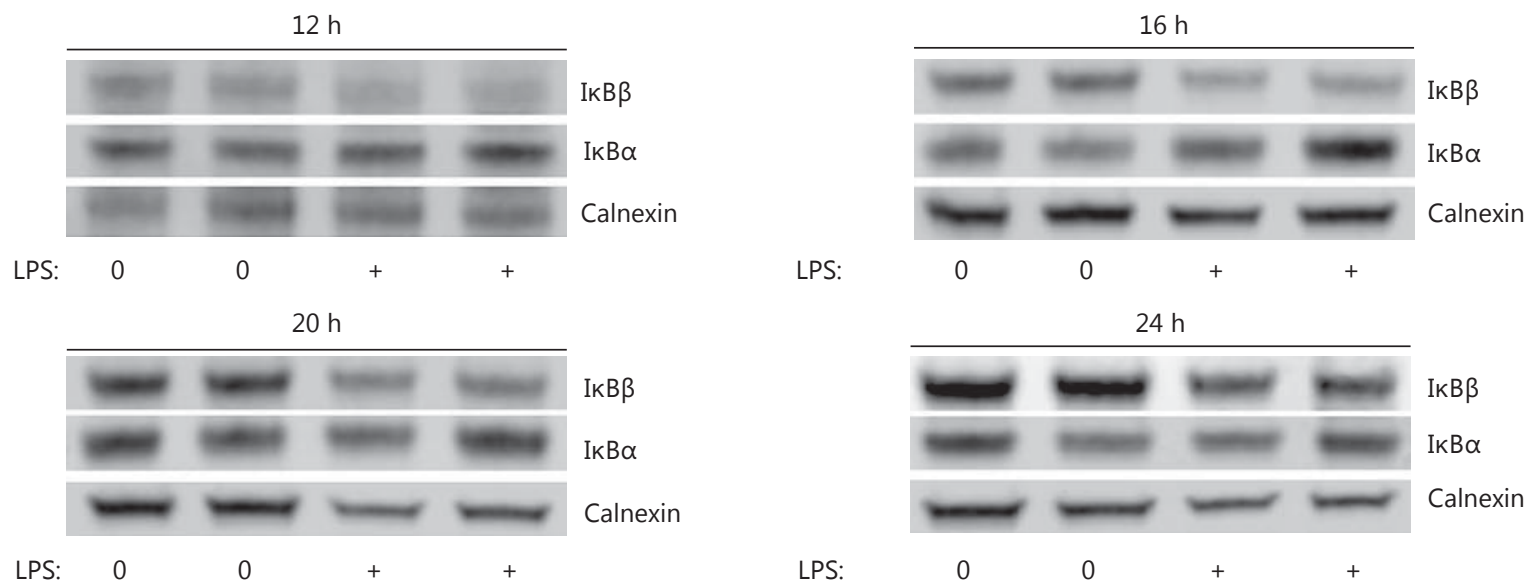

a

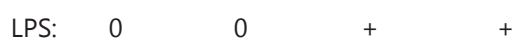

\section{$\operatorname{I\kappa B} \beta$ \\ $\mathrm{I \kappa} B \alpha$ \\ Calnexin}

LPS:
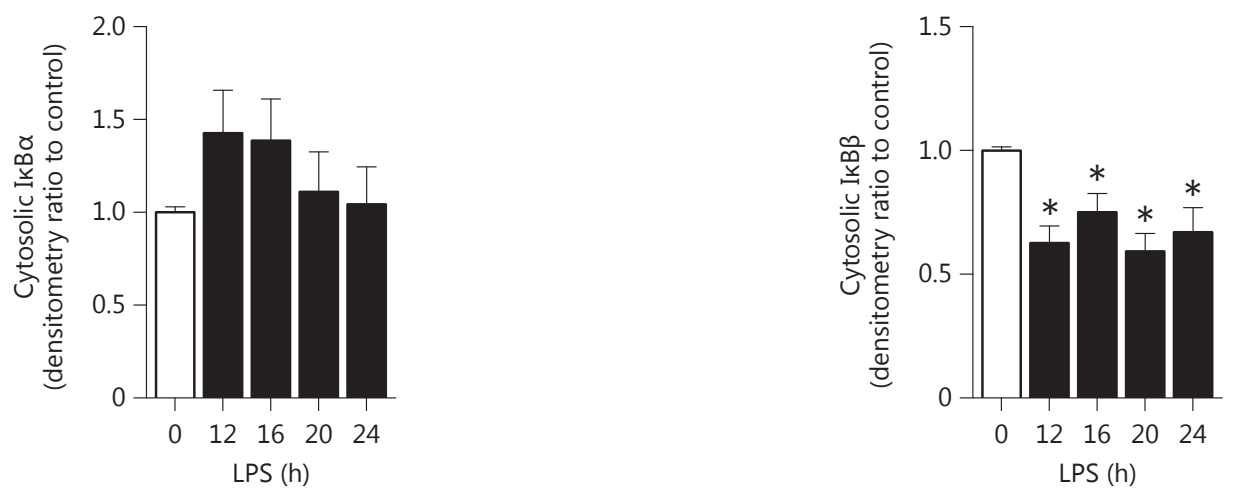

b PS (h)

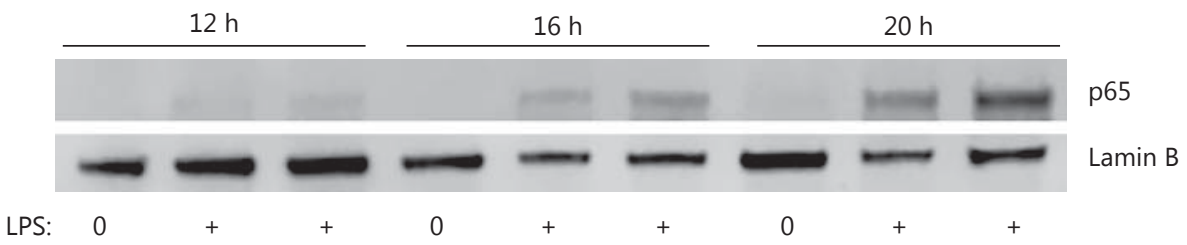

$24 \mathrm{~h}$

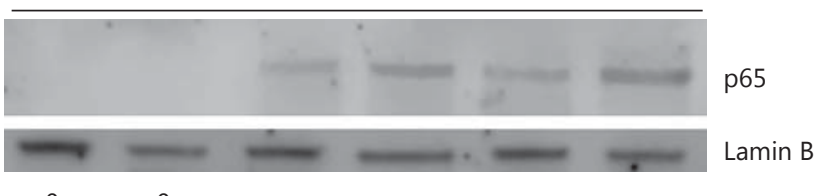

c LPS: $0 \quad 0 \quad 0 \quad+\quad+$

Fig. 3. LPS-induced hepatic COX-2 expression is temporally associated with NFkB activation. a, b Representative Western blot and densitometry of the $\mathrm{NF} \kappa \mathrm{B}$ inhibitory proteins I $\mathrm{KB} \alpha$ and $\mathrm{I} \kappa \mathrm{B} \beta$ in neonatal hepatic cytosolic fractions following sublethal endotoxemia (5 mg/kg i.p., 12-24 h) with calnexin as loading control.
Data are expressed as means \pm SEM; $\mathrm{n}=3-4 /$ time point. ${ }^{*} \mathrm{p}<0.05$ versus unexposed control. c Representative Western blot of the $\mathrm{NF \kappa B}$ subunit p65 in neonatal hepatic nuclear fractions following sublethal endotoxemia (5 mg/kg i.p., $12-24 \mathrm{~h}$ ) with lamin B as loading control. 
activation was temporally related to COX-2 expression,

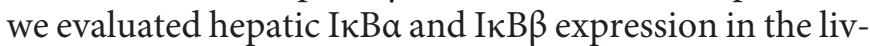
ers of adult mice exposed to sublethal endotoxemia and neonatal mice exposed to either lethal or sublethal endotoxemia. In the adult mice, exposure to sublethal endotoxemia induced I $\mathrm{kB} \alpha$ degradation by $2 \mathrm{~h}$ of exposure and, consistent with NFKB-dependent expression, levels returned to baseline by $4 \mathrm{~h}$ of exposure, ultimately exceeding baseline levels by $6 \mathrm{~h}$ of exposure (fig. 2a). Furthermore, endotoxemia induced I $\mathrm{B} \beta \beta$ degradation by $2 \mathrm{~h}$ of exposure, and levels began to recover by $4 \mathrm{~h}$ of exposure. In contrast to what was observed in adult mice, hepatic levels of I $\mathrm{KB} a$ in neonatal mice fell by $2 \mathrm{~h}$ of sublethal endotoxin exposure and only returned to baseline by $6 \mathrm{~h}$, but never exceeded baseline levels (fig. 2b). Furthermore, levels of $\mathrm{I} \kappa \mathrm{B} \beta$ remained low throughout the 6-hour exposure and showed no signs of recovery. Similarly, we observed that hepatic I $\mathrm{B} \beta \beta$ levels remained significantly below baseline levels after $6 \mathrm{~h}$ of exposure in neonatal mice exposed to lethal endotoxemia (fig. 2c).

Previous studies have demonstrated that reaccumulation of cytosolic I $\mathrm{B} B \mathrm{~B}$ is a marker of termination of $\mathrm{NF} \kappa \mathrm{B}$ activity [22]. Thus, we sought to determine the duration of depressed levels of hepatic I $\kappa B \beta$ in endotoxemic neonatal mice. Following a single exposure to sublethal endotoxemia, hepatic IKB $\beta$ remained below baseline at 12 , 16, 20 and $24 \mathrm{~h}$ of exposure (fig. 3a, b). This was associated with prolonged nuclear translocation of the NFKB subunit p65 that persisted through $24 \mathrm{~h}$ of exposure, indicative of ongoing NFKB activation (fig. 3c). These results show that in contrast to what was observed in adult mice, endotoxemia induces prolonged degradation of the NFKB inhibitory protein I $\kappa \mathrm{B} \beta$ in the liver of neonatal mice. This is associated with prolonged nuclear translocation of the NFkB subunit p65, a finding consistent with continued NFKB activation. These signaling events are temporally related to the prolonged COX-2 expression observed in endotoxemic neonatal mice.

\section{Endotoxemia Induces COX-2 Expression in Hepatic Macrophages}

Next, we sought to identify the cell type responsible for COX-2 production. To begin to answer this question, we performed immunohistochemical analysis of COX-2 in hepatic tissue isolated from endotoxemic neonatal mice. At $6 \mathrm{~h}$ of sublethal endotoxemia, immunohistochemistry revealed that hepatic COX-2 staining was increased and colocalized with hepatic macrophages (F4/80; fig. 4a). To corroborate these findings, we determined COX-2 mRNA expression in purified intrahepatic mononuclear cells isolated from the livers of endotoxemic neonatal mice; we chose this population of cells because it is inclusive of macrophage populations [21]. We found that when compared to hepatocytes, hepatic macrophages demonstrated significantly higher COX-2 expression (fig. 4b). Importantly, sublethal endotoxemia did not increase hepatic macrophage numbers in neonatal mice at a time when COX-2 expression begins to diverge from endotoxemic adults $(6 \mathrm{~h})$. These results implicate the resident hepatic macrophage as the primary source of increased COX-2 expression in endotoxemic neonatal mice.

\section{LPS-Induced COX-2 Expression Occurs via an}

NFאB-Dependent Mechanism in Macrophages

Next, we studied cells in culture in order to further investigate the link between LPS-induced NFKB activity in the macrophage and increased COX-2 expression. To confirm our finding that LPS induces COX-2 expression in macrophages, we compared the LPS-induced COX-2 expression of primary (BMDM) and immortalized (RAW 264.7) murine macrophages. Consistent with our in vivo findings, LPS induced robust COX-2 mRNA (fig. 5a) and protein (fig. 5b, d) expression in BMDM and RAW 264.7 cells. Importantly, pretreatment of RAW 264.7 macrophages with the pharmacologic IKK inhibitors, BAY 117085 and parthenolide, inhibited LPS-induced COX-2 mRNA (fig. 5c) and protein (fig. 5f) expression in a dosedependent manner. It is possible that the effect of BAY 11-7085 and parthenolide on LPS-induced COX-2 expression was due to off-target effects independent of NFkB signaling. To control for this, we transfected RAW 264.7 cells with plasmids to overexpress WT and DN I $\kappa \mathrm{B} \alpha$. Transfection with the $\mathrm{DN}$ I $\kappa \mathrm{B} \alpha$ plasmid results in expression of I $\mathrm{B} \mathrm{B} \alpha$ in which serine $32 / 36$ have been mutated to phenylalanine, preventing phosphorylation and subsequent degradation. Both WT and DN IкBa overexpression significantly attenuated LPS-induced COX-2 expression (fig. 5e). These results implicate LPS-induced $\mathrm{NFKB}$ activation in the transcriptional regulation of COX-2 in macrophages.

\section{Pharmacologic Inhibition of LPS-Induced NFKB}

Activity Attenuates Hepatic COX-2 Expression in vivo

To further evaluate the role of NFkB activity in LPSinduced hepatic COX-2 expression in vivo, we used pharmacologic NFkB inhibitors in our neonatal endotoxemia model. Specifically, neonatal mice were pretreated with BAY 11-7085 (1-10 mg/kg i.p., $1 \mathrm{~h}$ ) to pharmacologically inhibit IKK activity and prevent NFKB activation prior to LPS exposure. We noted a dose-dependent effect of 


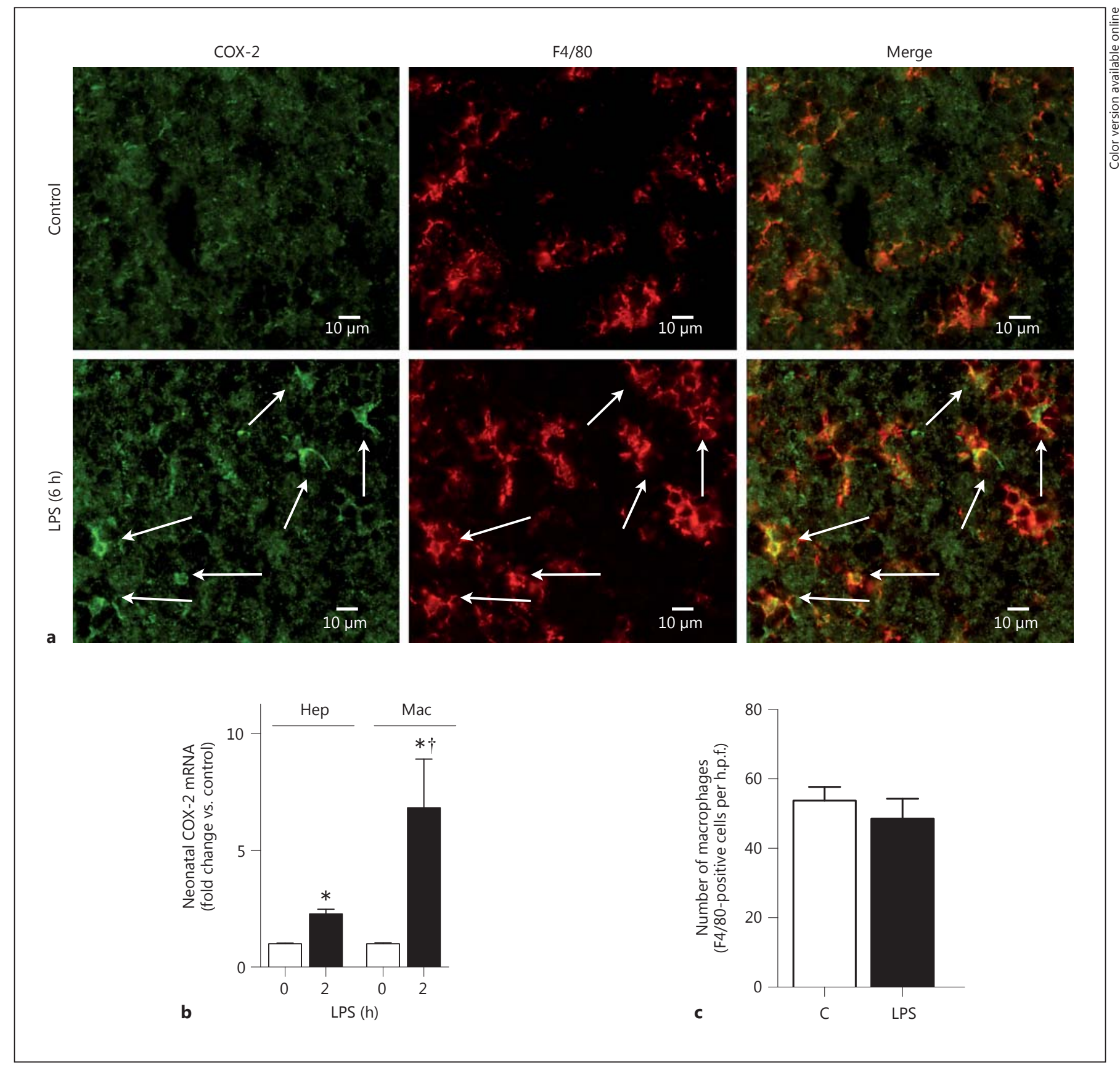

Fig. 4. Hepatic macrophages are responsible for LPS-induced hepatic COX-2 expression. a Representative immunofluorescent staining of control (top panel) and LPS-exposed ( $5 \mathrm{mg} / \mathrm{kg}$ i.p., $6 \mathrm{~h}$; bottom panel) neonatal liver sections stained with COX-2 (green) and macrophage marker F4/80 (red). Arrows indicate cells demonstrating COX-2 staining. b Fold increase of LPS-induced COX2 expression ( $5 \mathrm{mg} / \mathrm{kg}$ i.p., $2 \mathrm{~h}$ ) in isolated hepatocytes and isolated intrahepatic mononuclear cells. Hep = Hepatocytes; Mac = mac- rophages. Data expressed as means \pm SEM relative to unexposed macrophage control; $n=5 /$ time point. ${ }^{*} \mathrm{p}<0.05$ versus unexposed control; ${ }^{\dagger} \mathrm{p}<0.05$ versus LPS-exposed hepatocytes. c Quantitative analysis of F4/80-positive-stained cells was performed on neonatal mouse liver sections. Data are presented as the number of F4/80positive cells per high-powered field (h.p.f.; average of 5 sections per mouse). $\mathrm{C}=$ Control; LPS = LPS-exposed $(5 \mathrm{mg} / \mathrm{kg}$ i.p., $6 \mathrm{~h})$. 

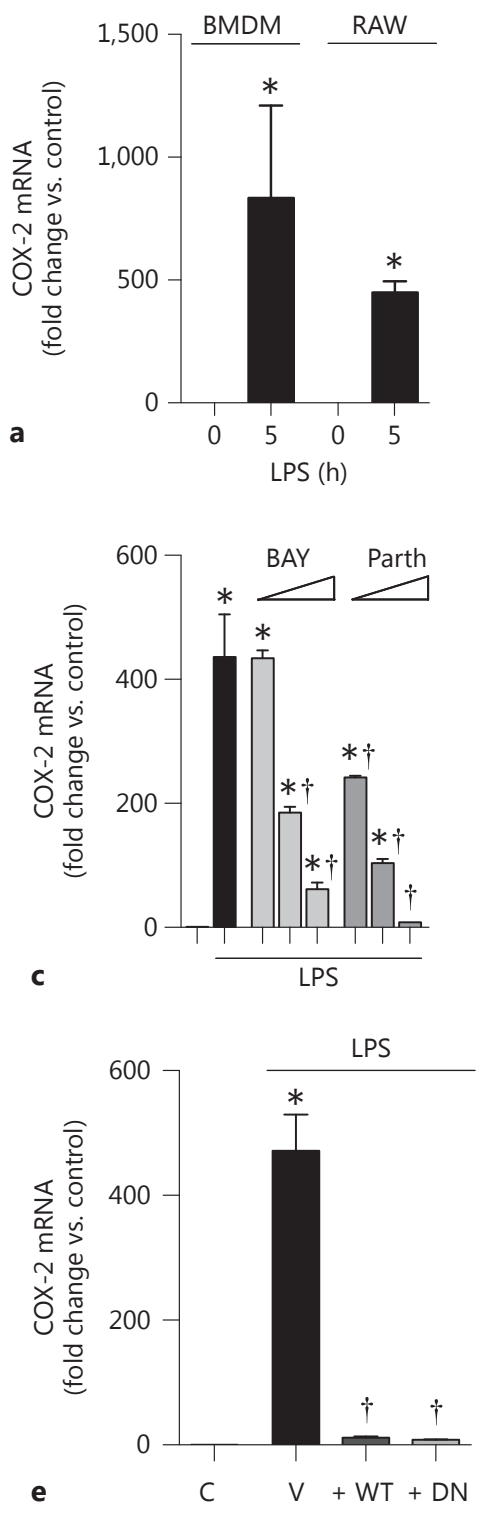

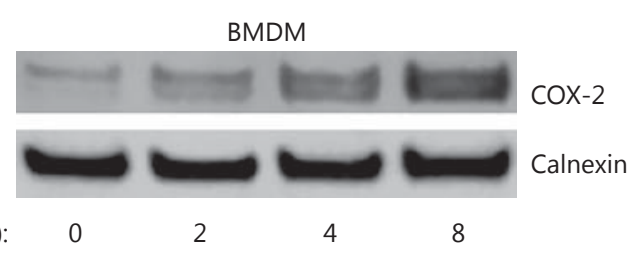

b

LPS (h):

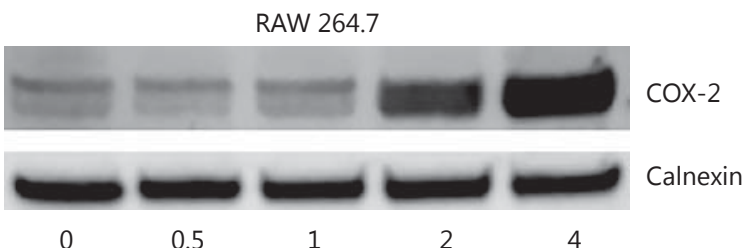

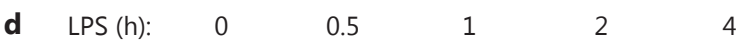

RAW 264.7

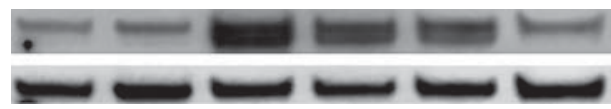

COX-2

Calnexin

LPS (4 h):

f $\operatorname{BAY}(\mu \mathrm{M})$ :

$\begin{array}{cccccc}- & 0 & + & + & + & + \\ 0 & 20 & 0 & 1 & 2 & 5\end{array}$

Fig. 5. NFkB regulates LPS-induced COX-2 expression in macrophages. a Fold change in LPS-induced COX-2 gene expression in primary (BMDM) and immortalized (RAW 264.7) macrophage cells. Values are means \pm SEM $(n=4 /$ time point $) .{ }^{*} p<0.05$ versus unexposed control. b Representative Western blot of COX-2 protein in ICR BMDM lysate following LPS exposure $(1 \mu \mathrm{g} / \mathrm{ml}, 0-8 \mathrm{~h})$ with calnexin as loading control. c COX-2 gene expression in RAW 264.7 pretreated with BAY 11-7085 (BAY) or parthenolide (Parth) (both 1-10 $\mu \mathrm{mol} / \mathrm{l}, 1 \mathrm{~h})$ prior to LPS exposure $(1 \mu \mathrm{g} / \mathrm{ml}$, $5 \mathrm{~h})$. Values are means \pm SEM $(\mathrm{n}=4 /$ time point $) .{ }^{*} \mathrm{p}<0.05$ versus unexposed control; ${ }^{\dagger} \mathrm{p}<0.05$ versus LPS-exposed. $\mathbf{d}$ Representa- tive Western blot of COX-2 protein in RAW 264.7 cell lysate following LPS exposure $(1 \mu \mathrm{g} / \mathrm{ml}, 0-4 \mathrm{~h})$ with calnexin as loading control. e COX-2 gene expression in cells transfected with either $\mathrm{I} \kappa \mathrm{B} \alpha$ expression plasmid (+ WT) or DN I $\kappa \mathrm{B} \alpha$ expression plasmid $(+\mathrm{DN})$ and exposed to LPS $(1 \mathrm{mg} / \mathrm{ml}, 5 \mathrm{~h})$. Values are means \pm SEM ( $\mathrm{n}=4$ /time point). $\mathrm{C}=$ Control; $\mathrm{V}=$ vehicle. ${ }^{*} \mathrm{p}<0.05$ versus unexposed control; ${ }^{\dagger} \mathrm{p}<0.05$ versus LPS-exposed. $\mathbf{f}$ Representative Western blot of COX-2 protein in RAW 264.7 macrophages following LPS exposure $(1 \mu \mathrm{g} / \mathrm{ml}, 4 \mathrm{~h})$ or pretreatment with BAY 11-7085 (1-5 $\mu \mathrm{M}, 1 \mathrm{~h})$ and LPS exposure. 

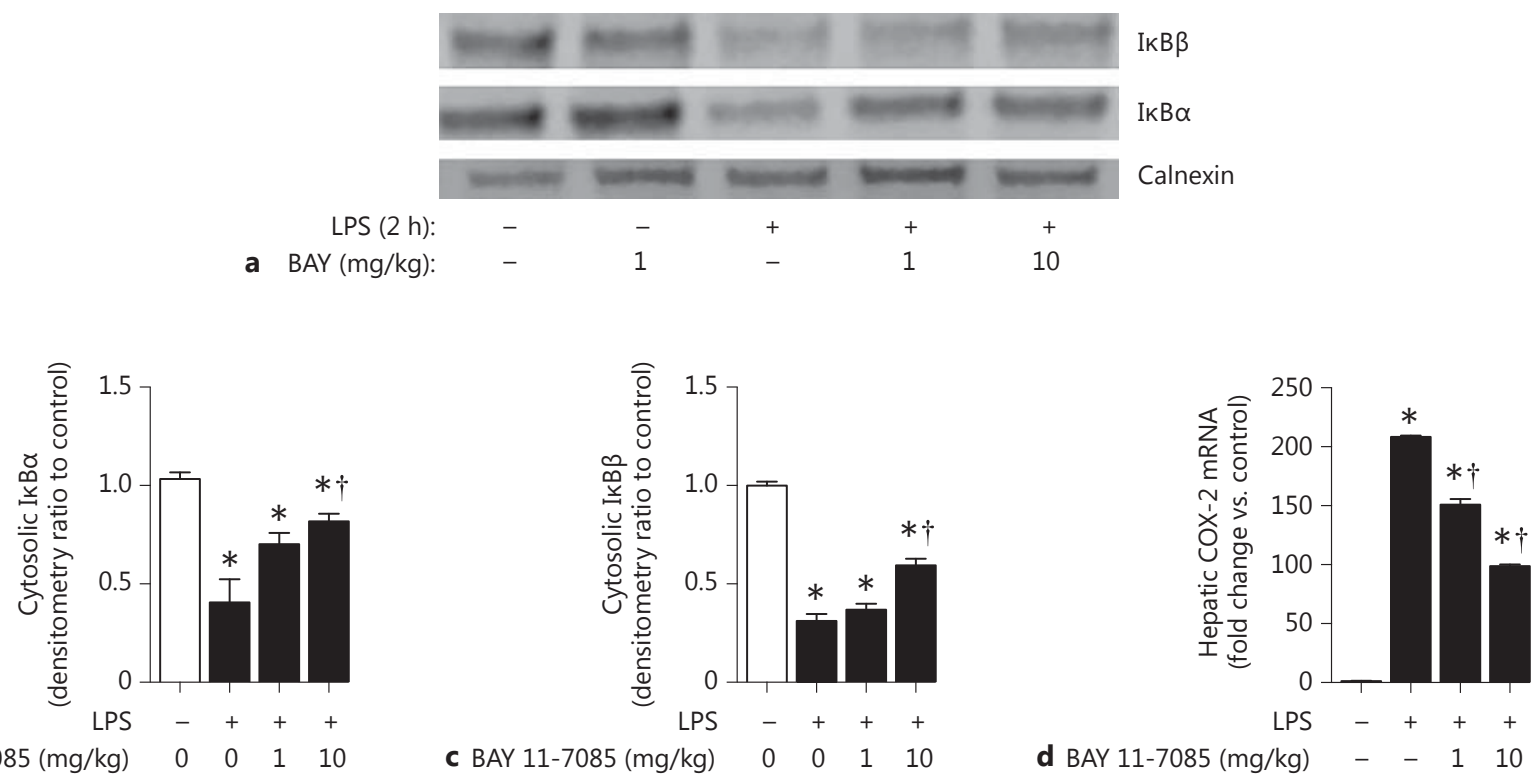

b BAY $11-7085(\mathrm{mg} / \mathrm{kg})$

C BAY $11-7085(\mathrm{mg} / \mathrm{kg})$

d BAY $11-7085(\mathrm{mg} / \mathrm{kg})$

Fig. 6. Hepatic LPS-induced COX-2 expression is NFkB-dependent. a Representative Western blot of cytosolic I $\mathrm{I} B a$ and I $\mathrm{I} B \beta$ expression in the neonatal liver following LPS exposure $(50 \mathrm{mg} / \mathrm{kg}$, $2 \mathrm{~h}$ ) or pretreatment with BAY 11-7085 (BAY, 1-20 mg/kg, $1 \mathrm{~h}$ ) prior to LPS exposure, with calnexin as loading control. b, c Densitometry of cytosolic I $\mathrm{B} B \alpha(\mathbf{b})$ or I $\mathrm{I} B \beta(\mathbf{c})$ following LPS exposure (50 mg/kg, $2 \mathrm{~h}$ ) or pretreatment with BAY 11-7085 (1-10 mg/kg,

pretreating neonatal mice with BAY 11-7085 (1-10 mg/ $\mathrm{kg}$ ) on LPS-induced hepatic IкB degradation (fig. 6a-c). Furthermore, we noted a dose-dependent effect of pretreating neonatal mice with BAY 11-7085 on LPS-induced hepatic COX-2 expression (fig. 6d). These results show that pharmacologic inhibition of LPS-induced $\mathrm{NF \kappa B}$ activity attenuates COX-2 expression, supporting

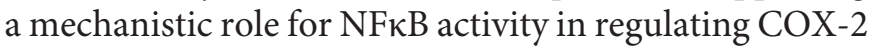
expression in vivo.

\section{Discussion}

Our results are interesting because they demonstrate that systemic inflammatory stress induces sustained COX-2 expression in the fetal and neonatal liver via an NFkB-dependent mechanism. These results reveal that the liver is an important source of COX-2 during systemic inflammatory stress in neonates (fig. 7). Inducible COX-2 expression is a key component of the TLR4-me-
$1 \mathrm{~h})$ prior to LPS exposure. $\mathbf{d}$ Fold increase of neonatal hepatic COX-2 expression following LPS exposure $(5 \mathrm{mg} / \mathrm{kg}, 2 \mathrm{~h}$ ) or pretreatment with BAY 11-7085 (1-10 mg/kg, $1 \mathrm{~h})$ prior to LPS exposure. Values are means \pm SEM ( $n=4 /$ time point $) . C=$ Control; $\mathrm{V}=$ vehicle. ${ }^{*} \mathrm{p}<0.05$ versus unexposed control; ${ }^{\dagger} \mathrm{p}<0.05$ versus LPS-exposed. diated innate immune response [6]. While our understanding of the developing immune system continues to evolve, the current paradigm maintains that the neonatal innate immune response is biased against a proinflammatory response [10]. However, this paradigm fails to explain why many of the major morbidities associated with preterm birth, i.e. bronchopulmonary dysplasia [23], periventricular leukomalacia [24], retinopathy of prematurity [25] and necrotizing enterocolitis [26], are marked by evidence of early and robust expression of proinflammatory mediators.

Clinical observations support the presence of increased COX-2 expression and activity in preterm neonates exposed to infectious stimuli. Clinical studies have shown that exposure to either chorioamnionitis or earlyonset sepsis increases the risk of developing a PDA [11, 12]. This is likely mediated by elevated circulating levels of prostaglandin and prostaglandin metabolites, including 6-keto-PGDF1, found in patients with PDA associated with infection [11]. Additionally, recent studies have 


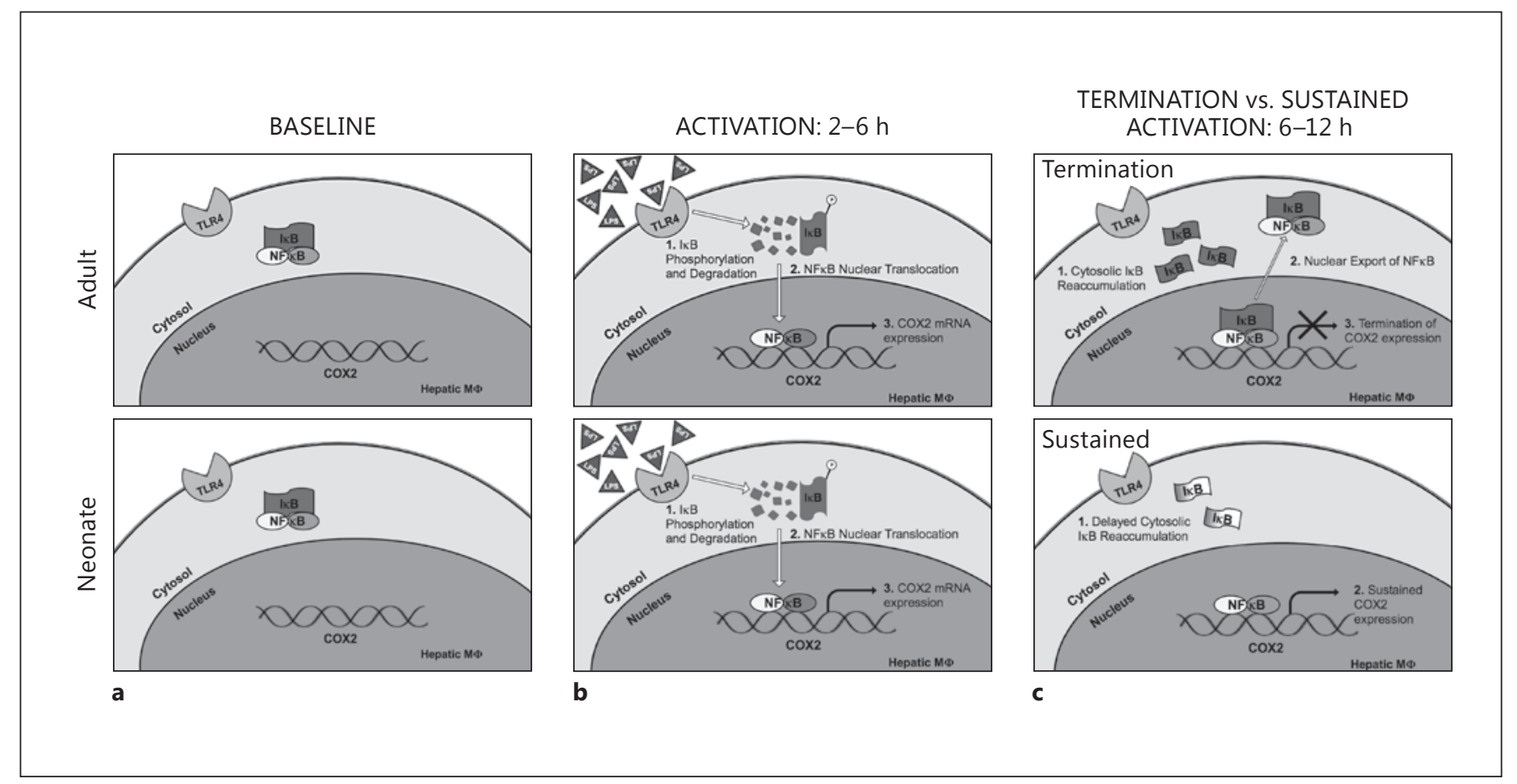

Fig. 7. Sustained NFKB signaling and prolonged COX-2 expression are unique to neonatal hepatic macrophages $(M \Phi)$. a NFkB is sequestered in the cytoplasm by I $\mathrm{kB}$ proteins in both adult (top row) and neonatal (bottom row) hepatic macrophages. b Following LPS exposure and TLR4 activation: 1 . IкBs are phosphorylated and degraded, 2. allowing NFKB nuclear translocation and 3. inducing COX-2 expression. This occurs between 2 and $6 \mathrm{~h}$ in both neonatal

shown that septic neonates with cardiorespiratory disturbances have increased PGE2 levels [13]. In this study, we used LPS as a TLR4 agonist to stimulate the neonatal innate immune response. Thus, our findings do not directly translate to observations made in humans infected with pathogenic organisms. However, our results provide insights into the transcriptional regulation and cellular source of increased COX-2 expression observed following TLR4 stimulation. Further studies are necessary to determine whether these same mechanisms explain the COX-2 expression and increased circulating prostaglandins observed in infected neonates.

It is important to recognize that COX-2 expression and activity may increase the risk of developing many of the common complications of prematurity. Clinically, elevated prostaglandins and lipid metabolites can be detected in babies exposed to antenatal inflammation that go on to develop bronchopulmonary dysplasia [27]. Similarly, COX-2 expression and activity has been implicated in laboratory models of bronchopulmonary dysplasia and adult macrophages. c At later time points (12-24 h), the termination of adult hepatic NFKB activity coincides with 1 . reaccumulation of I $\mathrm{BBs}, 2$. resulting in the export of $\mathrm{NF \kappa B}$ from the nucleus and 3. termination of COX-2 expression. In contrast, sustained activation of $\mathrm{NF \kappa B}$ occurs in neonatal hepatic macrophages due to 1 . delayed cytoplasmic reaccumulation of I $\kappa$ Bs, resulting in 2. prolonged $\mathrm{NF \kappa B}$ nuclear translocation and COX-2 expression.
[28], ROP [29], periventricular leukomalacia [30] and necrotizing enterocolitis [31]. However, global, pharmacologic COX-2 inhibition in neonates is complicated by reductions in renal and intestinal blood flow [32]. Our results demonstrated that in endotoxemic neonatal mice, inducible hepatic COX-2 expression is a central component of the neonatal innate immune response. Our finding of increased hepatic COX-2 expression in endotoxemic fetal and neonatal mice provides a potential mechanistic link between perinatal infection and the significant morbidities associated with prematurity. Furthermore, by identifying a specific organ and cellular source of increased COX-2 expression, there may be potential for the development of therapies to specifically target hepatic COX-2 expression, thereby avoiding complications associated with global COX-2 inhibition.

Previous studies have shown that, in adults, endotoxemia has organ- and cell type-specific effects on COX-2 expression [8]. Our findings, as well as the data presented in previous studies, support the hypothesis that organ- 
and cell type-specific expression of COX-2 occurs in endotoxemic neonatal animals as well. We have demonstrated that endotoxemia does not induce COX-2 expression in the lung, while inducing robust COX-2 expression (200- to 300 -fold) in the liver. However, endotoxemia does not induce COX-2 expression in the neonatal small or large bowel, and only modest (3- to 4-fold) expression in the neonatal stomach [33]. Although we have identified robust hepatic COX-2 expression in endotoxemic neonatal mice, how individual organs contribute to circulating prostaglandins is unknown. This may be of particular relevance during the neonatal period, where COX2 expression and increased levels of circulating prostaglandins have been associated with multiple morbidities [11-13, 28-31]. We speculate that identifying the source of circulating prostaglandins may reveal unique pharmacologic targets to limit prostaglandin synthesis and associated neonatal morbidities. Furthermore, by demonstrating end-organ differences in the LPS-induced expression of a central mediator of the innate immune response, we speculate that the liver may play a unique role in the pathogenesis of such morbidities. More work is needed to establish these relationships in order to identify the potential therapeutic targets.

While it is clear that COX-2 expression in response to endotoxemia is organ- and cell type-specific, the mechanisms underlying this finding are unknown. COX-2 expression is inducible and regulated at the transcriptional level [9]. We hypothesized that differences between neonatal and adult hepatic TLR4-mediated COX-2 expression may be transcriptionally determined. We interrogated the transcriptional regulation of COX-2 expression in endotoxemic mice. Previous studies have demonstrated that NFkB does not regulate LPS-induced COX-2 expression in enterocytes [31]. However, we found that $\mathrm{NF \kappa B}$ regulates hepatic COX-2 expression in endotoxemic neonatal mice. It has previously been recognized that COX-2 expression is subject to epigenetic regulation [34]. Although not investigated here, epigenetic modifications may explain the developmental organ- and cell type-specific expression of COX-2. More work is needed to answer these questions, and may reveal additional therapeutic targets to limit inducible COX-2 expression.

Previous studies have demonstrated that pulmonary TLR4-mediated NFKB signaling and target gene expression are developmentally regulated [15]. However, to our knowledge, other organ-specific developmental differences in TLR4-mediated NFKB signaling have not been reported. We report here that hepatic TLR4-mediated $\mathrm{NF \kappa B}$ activation is developmentally regulated. However, in contrast to the neonatal lung, the neonatal liver exhibits prolonged $\mathrm{NF \kappa B}$ signaling, resulting in sustained COX-2 expression. Although not reported here, it is likely that COX-2 is not the only NFKB target demonstrating this expression pattern. Identifying other NFkB target genes that demonstrate sustained hepatic expression will provide further insight into the unique regulation of the innate immune response in the neonatal period. Additionally, we have shown that LPS-induced COX-2 expression is enriched in the neonatal macrophage. Whether sustained NFKB activation is specific to these cells or present in any other cells has yet to be determined. Our findings provide mechanistic insights into the signaling pathways and cells responsible for LPS-induced COX-2 expression in a neonatal model of systemic inflammatory stress, and may allow us to gain a better understanding of the neonatal innate immune response.

Our study has a number of limitations. Using our endotoxemic model and based on previous reports showing the liver as a primary source of TLR4-mediated COX-2 expression in adults, we focused on the neonatal liver and lung. However, endotoxin has been reported to induce COX-2 expression in isolated neonatal murine cardiomyocytes and neonatal bovine peripheral blood mononuclear cells $[35,36]$. We did not look at cell type-specific COX-2 expression in other organs including the brain. These studies will be important in order to evaluate the effect of local COX-2 expression and activity in the neonatal mouse. Furthermore, we did not assess the effect of attenuating LPS-induced, NFkB-regulated COX-2 expression on the outcomes of endotoxemic neonatal mice. Previous studies have shown a detrimental effect on global inhibition of NFKB activity in endotoxemic mice [15]. Furthermore, due to its important role in vascular and pulmonary development, complete NFKB inhibition is detrimental in the neonatal period $[37,38]$. To negate the effects of complete NFKB inhibition during this period, more specific inhibitors of sustained NFKB signaling are necessary. Finally, while the proinflammatory role of COX-2 is clear, it also plays a clear role in the resolution of inflammation [39]. The complex pro- and anti-inflammatory role played by COX-2 during systemic inflammatory stress is highlighted by the finding that, in mice, COX-2 inhibition improves survival in endotoxemia but increases mortality during polymicrobial sepsis [40]. Thus, the study that focused here on the mechanisms underlying the LPS-induced COX-2 expression in neonatal mice must be balanced with future studies focused on the physiologic and developmental impact of attenuating this central aspect of the innate immune response. 


\section{Conclusions}

Endotoxemia induces COX-2 expression in a developmentally regulated, organ- and cell type-specific manner. Fetal, neonatal and adult mice experience robust hepatic COX-2 expression. Importantly, sustained hepatic COX2 expression is NFkB-dependent and unique to neonatal mice. We speculate that a similar mechanism is responsible for the hepatic COX-2 expression in fetal mice, and is present as early as e15. Our results reveal that during the perinatal period, hepatic COX-2 expression is an important marker of an intact and robust innate immune response to systemic inflammatory stress. Targeted inhi- bition of hepatic COX-2 expression may prevent neonatal morbidities associated with perinatal systemic inflammatory stress.

\section{Acknowledgments}

This work was supported by NIH grant K08 HL098562 to C.J.W. We would like to thank Elizabeth Hill and Megan Gossling, MD, for their technical assistance with the experiments presented.

\section{Disclosure Statement}

The authors declare no conflicts of interest.

\section{References}

$\checkmark 1$ Blencowe H, Cousens S, Oestergaard MZ, Chou D, Moller AB, Narwal R, Adler A, Vera Garcia C, Rohde S, Say L, Lawn JE: National, regional, and worldwide estimates of preterm birth rates in the year 2010 with time trends since 1990 for selected countries: a systematic analysis and implications. Lancet 2012;379: 2162-2172.

-2 Newton ER: Preterm labor, preterm premature rupture of membranes, and chorioamnionitis. Clin Perinatol 2005;32:571-600.

-3 Stoll BJ, Hansen NI, Bell EF, Walsh MC, Carlo WA, Shankaran S, Laptook AR, Sanchez PJ, Van Meurs KP, Wyckoff M, Das A, Hale EC, Ball MB, Newman NS, Schibler K, Poindexter BB, Kennedy KA, Cotten CM, Watterberg KL, D’Angio CT, DeMauro SB, Truog WE, Devaskar U, Higgins RD; Eunice Kennedy Shriver National Institute of Child Health; Human Development Neonatal Research Network: Trends in care practices, morbidity, and mortality of extremely preterm neonates, 1993-2012. JAMA 2015;314:1039-1051.

4 Bersani I, Thomas W, Speer CP: Chorioamnionitis - the good or the evil for neonatal outcome? J Matern Fetal Neonatal Med 2012; 25(suppl 1):12-16.

5 Klinger G, Levy I, Sirota L, Boyko V, LernerGeva L, Reichman B; Israel Neonatal Network: Outcome of early-onset sepsis in a national cohort of very low birth weight infants. Pediatrics 2010;125:e736-e740.

-6 Kang YJ, Wingerd BA, Arakawa T, Smith WL: Cyclooxygenase-2 gene transcription in a macrophage model of inflammation. J Immunol 2006; 177:8111-8122.

7 Aronoff DM: Cyclooxygenase inhibition in sepsis: is there life after death? Mediators Inflamm 2012;2012:696897.
8 Connor AJ, Chen LC, Joseph LB, Laskin JD, Laskin DL: Distinct responses of lung and liver macrophages to acute endotoxemia: role of Toll-like receptor 4. Exp Mol Pathol 2013;94: 216-227.

-9 Simmons DL, Botting RM, Hla T: Cyclooxygenase isozymes: the biology of prostaglandin synthesis and inhibition. Pharmacol Rev 2004;56:387-437.

10 Levy O: Innate immunity of the newborn: basic mechanisms and clinical correlates. Nat Rev Immunol 2007;7:379-390.

11 Gonzalez A, Sosenko IR, Chandar J, Hummler $\mathrm{H}$, Claure N, Bancalari E: Influence of infection on patent ductus arteriosus and chronic lung disease in premature infants weighing 1,000 g or less. J Pediatr 1996;128: 470-478.

12 Soraisham AS, Singhal N, McMillan DD, Sauve RS, Lee SK; Canadian Neonatal Network: a multicenter study on the clinical outcome of chorioamnionitis in preterm infants. Am J Obstet Gynecol 2009;200:372:e1-6.

13 Siljehav V, Hofstetter AM, Leifsdottir K, Herlenius E: Prostaglandin E2 mediates cardiorespiratory disturbances during infection in neonates. J Pediatr 2015;167:1207-1213.e3.

14 Blackwell TS, Yull FE, Chen CL, Venkatakrishnan A, Blackwell TR, Hicks DJ, Lancaster LH, Christman JW, Kerr LD: Multiorgan nuclear factor kappa $\mathrm{B}$ activation in a transgenic mouse model of systemic inflammation. Am J Respir Crit Care Med 2000;162: 1095-1101.

-15 Alvira CM, Abate A, Yang G, Dennery PA, Rabinovitch M: Nuclear factor-kappaB activation in neonatal mouse lung protects against lipopolysaccharide-induced inflammation. Am J Respir Crit Care Med 2007;175: 805-815.
16 Vancurova I, Bellani P, Davidson D: Activation of nuclear factor-kappaB and its suppression by dexamethasone in polymorphonuclear leukocytes: newborn versus adult. Pediatr Res 2001;49:257-262.

17 Wright CJ, Zhuang T, La P, Yang G, Dennery PA: Hyperoxia-induced NF-kappaB activation occurs via a maturationally sensitive atypical pathway. Am J Physiol Lung Cell Mol Physiol 2009;296:L296-L306.

18 Hayden MS, Ghosh S: Signaling to NF-kappaB. Genes Dev 2004;18:2195-2224.

19 Hoffmann A, Levchenko A, Scott ML, Baltimore D: The IkappaB-NF-kappaB signaling module: temporal control and selective gene activation. Science 2002;298:1241-1245.

20 Elovitz MA, Wang Z, Chien EK, Rychlik DF, Phillippe M: A new model for inflammationinduced preterm birth: the role of platelet-activating factor and Toll-like receptor-4. Am J Pathol 2003;163:2103-2111.

21 McKenna S, Gossling M, Bugarini A, Hill E, Anderson AL, Rancourt RC, Balasubramaniyan N, El Kasmi KC, Wright CJ: Endotoxemia induces IkappaBbeta/NF-kappaB-dependent endothelin-1 expression in hepatic macrophages. J Immunol 2015;195:3866-3879.

22 Ghosh S, May MJ, Kopp EB: NF-kappa B and Rel proteins: evolutionarily conserved mediators of immune responses. Annu Rev Immunol 1998;16:225-260.

23 Wright CJ, Kirpalani H: Targeting inflammation to prevent bronchopulmonary dysplasia: can new insights be translated into therapies? Pediatrics 2011;128:111-126.

24 Elitt CM, Rosenberg PA: The challenge of understanding cerebral white matter injury in the premature infant. Neuroscience 2014;276: 216-238. 
25 Lee J, Dammann O: Perinatal infection, inflammation, and retinopathy of prematurity. Semin Fetal Neonatal Med 2012;17:26-29.

$>26$ De Plaen IG: Inflammatory signaling in necrotizing enterocolitis. Clin Perinatol 2013;40: 109-124.

$>27$ Watterberg KL, Demers LM, Scott SM, Murphy S: Chorioamnionitis and early lung inflammation in infants in whom bronchopulmonary dysplasia develops. Pediatrics 1996; 97:210-215.

28 Britt RD Jr, Velten M, Tipple TE, Nelin LD, Rogers LK: Cyclooxygenase-2 in newborn hyperoxic lung injury. Free Radic Biol Med 2013;61:502-511.

29 Wilkinson-Berka JL, Alousis NS, Kelly DJ, Gilbert RE: Cox-2 inhibition and retinal angiogenesis in a mouse model of retinopathy of prematurity. Invest Ophthalmol Vis Sci 2003; 44:974-979.

30 Carty ML, Wixey JA, Reinebrant HE, Gobe G, Colditz PB, Buller KM: Ibuprofen inhibits neuroinflammation and attenuates white matter damage following hypoxia-ischemia in the immature rodent brain. Brain Res 2011; 1402:9-19.
31 Grishin AV, Wang J, Potoka DA, Hackam DJ, Upperman JS, Boyle P, Zamora R, Ford HR: Lipopolysaccharide induces cyclooxygenase-2 in intestinal epithelium via a noncanonical p38 MAPK pathway. J Immunol 2006; 176:580-588.

32 Hamrick SE, Hansmann G: Patent ductus arteriosus of the preterm infant. Pediatrics 2010;125:1020-1030

33 Martinez FE, Reno C, Trevenen CL, Hart DA, Belik J: Age-dependent changes in the regulation of cyclooxygenases in the gastrointestinal tract after Gram-negative endotoxemia. J Pediatr Gastroenterol Nutr 2001;33:165-170.

34 Harizi H: Epigenetic regulations of inflammatory cyclooxygenase-derived prostanoids: molecular basis and pathophysiological con sequences. Mediators Inflamm 2015;2015: 841097.

35 Shen E, Fan J, Chen R, Yee SP, Peng T: Phospholipase Cgamma1 signalling regulates lipopolysaccharide-induced cyclooxygenase-2 expression in cardiomyocytes. J Mol Cell Cardiol 2007;43:308-318.
6 Dawes ME, Tyler JW, Marsh AE, Larson RL, Steevens BJ, Lakritz J: In vitro effects of lactoferrin on lipopolysaccharide-induced proliferation, gene expression, and prostanoid production by bovine peripheral blood mononuclear cells. Am J Vet Res 2008;69:1164-1170.

37 Hou Y, Li F, Karin M, Ostrowski MC: Analysis of the IKKbeta/NF-kappaB signaling pathway during embryonic angiogenesis. Dev Dyn 2008;237:2926-2935.

38 Iosef C, Alastalo TP, Hou Y, Chen C, Adams ES, Lyu SC, Cornfield DN, Alvira CM: Inhibiting NFkappaB in the developing lung disrupts angiogenesis and alveolarization. Am J Physiol Lung Cell Mol Physiol 2012; 302:L1023-L1036.

39 Gilroy DW, Colville-Nash PR, Willis D, Chivers J, Paul-Clark MJ, Willoughby DA: Inducible cyclooxygenase may have anti-inflammatory properties. Nat Med 1999;5:698-701.

40 Reddy RC, Chen GH, Tateda K, Tsai WC, Phare SM, Mancuso P, Peters-Golden M, Standiford TJ: Selective inhibition of Cox-2 improves early survival in murine endotoxemia but not in bacterial peritonitis. Am J Physiol Lung Cell Mol Physiol 2001; 281:L537-L543. 